\title{
Involving patients in cardiovascular risk management with nurse-led clinics: a cluster randomized controlled trial
}

\author{
Marije S. Koelewijn-van Loon MSc, Trudy van der Weijden PhD MD, Ben van Steenkiste PhD, \\ Gaby Ronda PhD, Bjorn Winkens PhD, Johan L. Severens PhD, Michel Wensing PhD, \\ Glyn Elwyn PhD, Richard Grol PhD
}

\section{ABSTRACT}

Background: Preventive guidelines on cardiovascular risk management recommend lifestyle changes. Support for lifestyle changes may be a useful task for practice nurses, but the effect of such interventions in primary prevention is not clear. We examined the effect of involving patients in nurse-led cardiovascular risk management on lifestyle adherence and cardiovascular risk.

Methods: We performed a cluster randomized controlled trial in 25 practices that included 615 patients. The intervention consisted of nurse-led cardiovascular risk management, including risk assessment, risk communication, a decision aid and adapted motivational interviewing. The control group received a minimal nurse-led intervention. The self-reported outcome measures at one year were smoking, alcohol use, diet and physical activity. Nurses assessed 10-year cardiovascular mortality risk after one year.

Results: There were no significant differences between the intervention groups. The effect of the intervention on the consumption of vegetables and physical activity was small, and some differences were only significant for subgroups. The effects of the intervention on the intake of fat, fruit and alcohol and smoking were not significant. We found no effect between the groups for cardiovascular 10-year risk.

Interpretation: Nurse-led risk communication, use of a decision aid and adapted motivational interviewing did not lead to relevant differences between the groups in terms of lifestyle changes or cardiovascular risk, despite significant within-group differences.

I $t$ is not clear if programs for lifestyle change are effective in the primary prevention of cardiovascular diseases. Some studies have shown lifestyle improvements with cardiovascular rehabilitation programs, ${ }^{1-3}$ and studies in primary prevention have suggested small, but potentially important, reductions in the risk of cardiovascular disease. However, these studies have had limitations and have recommended further research. ${ }^{4,5}$ According to national and international guidelines for cardiovascular risk management, measures to prevent cardiovascular disease, such as patient education and support for lifestyle change, can be delegated to practice nurses in primary care. ${ }^{6-8}$ However, we do not know whether the delivery of primary prevention programs by practice nurses is effective. We also do no know the effect of nurse-led prevention, including shared decisionmaking and risk communication, on cardiovascular risk.

Because an unhealthy lifestyle plays an important role in the development of cardiovascular disease, ${ }^{9,10}$ preventive guidelines on cardiovascular disease and diabetes recommend education and counselling about smoking, diet, physical exercise and alcohol consumption for patients with moderately and highly increased risk. ${ }^{6,11}$ These patients are usually monitored in primary care practices. The adherence to lifestyle advice ranges from $20 \%$ to $90 \%,,^{12-15}$ and improving adherence requires effective interventions, comprising cognitive, behavioural and affective components (strategies to influence adherence to lifestyle advice via feelings and emotions or social relationships and social supports). ${ }^{16}$ Shared treatment decisions are highly preferred. Informed and shared decisionmaking requires that all information about the cardiovascular risk and the pros and cons of the risk-reduction options be shared with the patient, and that the patients' individual values, personal resources and capacity for self-determination be respected. ${ }^{17-19}$ In our cardiovascular risk reduction study, ${ }^{20}$ we developed an innovative implementation strategy that included a central role for practice nurses. Key elements of our intervention included risk assessment, risk communication, use of a decision aid and adapted motivational interviewing (Box 1)..$^{19,21,22}$

In the present study, we investigated whether a nurse-led intervention in primary care had a positive effect on lifestyle and 10-year cardiovascular risk. We hypothesized that involving patients in decision-making would increase adherence to lifestyle changes and decrease the absolute risk of 10-year cardiovascular mortality.

From the CAPHRI School for Public Health and Primary Care, Departments of General Practice (Koelewijn-van Loon, van der Weijden, van Steenkiste, Ronda, Grol), Health Organisation, Policy and Economics (Severens) and Methodology and Statistics (Winkens), Maastricht University, Maastricht, the Netherlands; the Department of Epidemiology and Medical Technology assessment (Severens), University Hospital Maastricht, Maastricht, the Netherlands; the Scientific Institute for Quality of HealthCare (van der Weijden, Wensing, Elwyn, Grol), Radboud University Nijmegen, the Netherlands: and the Department of Primary Care and Public Health (Elwyn), School of Medicine, Cardiff University, Cardiff, UK

Cite as CMAJ 2009. DOI:10.1503/cmaj.081591 


\section{Box 1: Key features of the nurse-led intervention}

- Risk assessment (intervention and control): The absolute 10-year mortality risk from cardiovascular diseases was assessed with use of a risk table from the Dutch guidelines (for patients without diabetes) or the UK Prospective Diabetes Study risk engine (for patients with diabetes). ${ }^{6,23}$ Nurses in the control group continued to provide usual care after this step.

- Risk communication (intervention only): Nurses informed the patients of their absolute 10-year cardiovascular mortality risk using a risk communication tool developed for this study. ${ }^{24-37}$

- Decision support (intervention only): Nurses provied support to the patients using an updated decision aid. ${ }^{28}$ This tool facilitated the nurses' interaction with the patients to arrive at informed, value-based choices for risk reduction. The tool provided information about the options and their associated relevant outcomes.

- Adapted motivational interviewing (intervention only): Nurses discussed the options for risk reduction. The patient's personal values were elicited using adapted motivational interviewing.

\section{Methods}

\section{Practices and participants}

The Improving Patient Adherence to Lifestyle Advice (IMPALA) study (Current Controlled Trials registration no. ISRCTN 51556722) is a cluster randomized controlled trial involving 25 practices and 615 patients in the Netherlands. Measurements were made at baseline and after 1 year. ${ }^{21}$ We included practices that employed a practice nurse and used electronic patients records. Practices were invited by letter and were visited by 1 or 2 of the researchers. We recruited practices in October and November 2005. The ethics committee of Maastricht University approved this study.

After stratification into 4 geographical regions, an independent statistician performed central block randomization to allocate 13 practices to the intervention group and 12 practices to the control group. The nurses could not be blinded to the intervention because of the required training. To minimize potential bias, we informed patients about the aim of the study but not about the intervention or control groups. The outline of the study is shown in Appendix 1 (available online at www.cmaj.ca/cgi/content/full/cmaj.081591/DC1).

Nurses and general practitioners enrolled adult patients eligible for cardiovascular risk management who met one or more of the following criteria (based on the Dutch National Guideline for cardiovascular risk management ${ }^{6}$ ): blood pressure $\geq 140 \mathrm{~mm} \mathrm{Hg}$ or receiving treatment for high blood pressure; total cholesterol $\geq 6.5 \mathrm{mmol} / \mathrm{L}$ or receiving treatment for high cholesterol; smoker aged $\geq 50$ years (men) or $\geq 55$ years (women); diabetes; a positive family history of cardiovascular disease; and visible obesity (based on the physician's opinion). We excluded patients who had existing cardiovascular disease, those with familial hypercholesterolemia only and those whose care was primarily managed in secondary care.

Patients were enrolled from February 2006 to August 2006. The inclusion method was consistent with a clinical approach to primary prevention. Patients received a written consent form and a baseline questionnaire before the intervention. A followup questionnaire was sent to patients' home address after 1 year. A more detailed description of the inclusion and the logistics of the measurements can be found in the study protocol. ${ }^{21}$

\section{Intervention}

In both groups, general practitioners delegated the task of cardiovascular risk management to the practice nurses. Nurses in the control group received a 2-hour training session on risk assessment, while practice nurses in the intervention group received a 2-day training program involving 4 strategies: risk assessment, risk communication, distribution of a decision aid and adapted motivational interviewing.

Motivational interviewing is a directive, client-centred counselling style that helps clients explore and resolve ambivalence about behaviour change. ${ }^{29}$ Adapted motivational interviewing has been used to assess patients' motivations for behaviour change and build motivation for healthy behaviours, to clarify values, to achieve goal setting and concrete action plans and to reveal both positive and negative consequences of behaviour change..$^{30-32}$ Motivational interviewing is a useful tool, in addition to the use of a risk chart and a decision aid, to uncover implementation problems ${ }^{18}$ and to reach a shared decision on cardiovascular risk management.

Each patient in the intervention group had 2 face-to-face meetings (15-20 min) with a practice nurse. This gave the patients time between meetings to reflect on the information received. ${ }^{19}$

During the first meeting, the nurses explained to the patients their 10-year risk of cardiovascular mortality by use of the risk communication tool. This tool was given to the patients. For patients whose risk was increased, the nurses explained the options for risk reduction and gave the patients a decision aid to review at home. During the second meeting, the nurses increased the patients' confidence by asking questions about the decision aid (e.g., did the patient understand the information). The nurses set the adgenda for the meeting in cooperation with the patients by asking what they wanted to talk about. An agenda-setting chart was used to support this process. The nurses guided the patients in formulating their main personal goals for lifestyle change. The nurses consulted with the general practitioners if medication was being considered.

Nurses used a 10-minute telephone consultation to initiate follow-up. ${ }^{16,20}$ During the telephone call, the nurses used motivational interviewing. They set the agenda, explored the importance of the personal goal that was chosen during the first meeting and increased the patients' confidence. The nurses guided the patients in formulating their main goals for lifestyle change, gave the patients support and referred them to local facilities as necessary.

The intervention is described more extensively in the IMPALA study protocol. ${ }^{21}$

\section{Outcomes}

The effect measures were self-reported lifestyle (smoking status, saturated fat intake, fruit and vegetable consumption, physical activity and alcohol use). We used a composite 
adherence score as well as scores for each of the 6 lifestyle outcomes. We also assessed the absolute 10-year mortality risk from cardiovascular disease, as measured by the practice nurses. ${ }^{6}$ The instruments are described in the IMPALA study protocol $^{21}$ and in Appendix 2 (available online at www.cmaj .ca/cgi/content/full/cmaj.081591/DC1)

Smoking was measured by use of a 2-item questionnaire to asses smoking status (yes v. no). ${ }^{33}$ Fat intake was measured using the Dutch Fat list, ${ }^{34}$ a questionnaire with 35 questions that gives a score (range 0-80) for saturated fat intake. The consumption of fruits and vegetables was measured by use of the Food Frequency Questionnaire, ${ }^{35}$ a 10 -item questionnaire to assess the weekly intake of fruits and vegetables. Physical exercise was assessed with a modified Dutch version of the Community Healthy Activities Model Program for Seniors (CHAMPS) questionnaire, ${ }^{36}$ a 15 -item questionnaire to assess the weekly frequency of participation and weekly duration of moderate-intensity (or greater) physical activity. Alcohol intake was measured using a 2-item questionnaire about the frequency and quantity of alcohol use, resulting in a score of drinking above the national recommendation (males: $\leq 3$ alcohol units per day, females: $\leq 2$ alcohol units per day). For smoking, consumption of fat, fruits and vegetables, and physical activity, meeting the national recommendation was also used as a measure. The 10-year risk of cardiovascular mortality was based on age, sex, smoking, blood pressure and cholesterol ratio. For patients without diabetes, the risk was calculated with help of the risk estimator of SCORE, ${ }^{37}$ which is used in the Dutch national guideline for cardiovascular risk management. ${ }^{38}$ The 10-year cardiovascular mortality risk of patients with diabetes was calculated with the UK Prospective Diabetes Study risk engine. ${ }^{39}$

\section{Sample size}

This study was powered to detect an absolute mean difference between groups of $15 \%(50 \%-65 \%)$ in patients' self-reported adherence to lifestyle advice (50\% is the average adherence to lifestyle advice in patients with chronic diseases. ${ }^{15}$ The sample

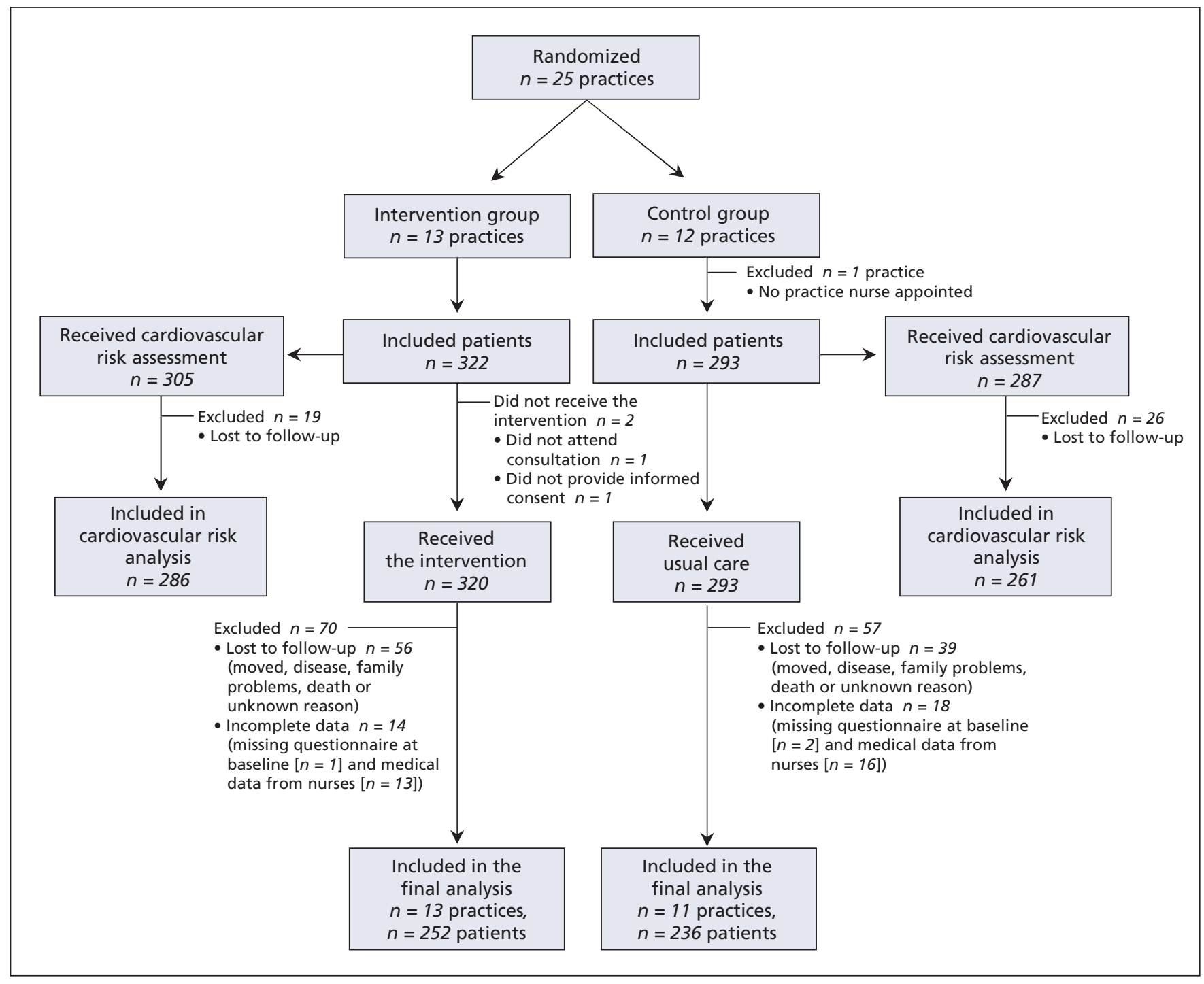

Figure 1: Flow diagram of the progress of clusters and individuals through the phases of the trial. 
Table 1: Characteristics of the general practices, nurses and patients included in the study of nurse-led interventions for cardiovascular risk management

\begin{tabular}{|c|c|c|}
\hline \multirow[b]{2}{*}{ Group; baseline characteristic } & \multicolumn{2}{|c|}{ Mean (SD)* } \\
\hline & Intervention & Control \\
\hline Practice & $n=13$ & $n=11$ \\
\hline No. of patients per practice & $7894(6642)$ & 6729 (3076) \\
\hline No. of general practitioners per practice & $4(3)$ & $4(1)$ \\
\hline Practice nurses & $n=13$ & $n=11$ \\
\hline Age, yr & $38(7)$ & $39(9)$ \\
\hline Sex, female, no. (\%) of nurses & $13(100)$ & $11(100)$ \\
\hline \multicolumn{3}{|c|}{ Work experience as a practice nurse focused on: } \\
\hline \multicolumn{3}{|l|}{ Diabetes } \\
\hline Yes, no. (\%) of nurses & $8(53)$ & $9(82)$ \\
\hline No. of years & $3.4(1.3)$ & $3.8(1.4)$ \\
\hline \multicolumn{3}{|l|}{ Cardiovascular risk } \\
\hline Yes, no. (\%) of nurses & $12(80)$ & $9(82)$ \\
\hline No. of years & $1.8(1.3)$ & $1.6(1.0)$ \\
\hline \multicolumn{3}{|l|}{ Hypertension } \\
\hline Yes, no. (\%) of nurses & $12(80)$ & $8(73)$ \\
\hline No. of years & $3.7(5.3)$ & $2.7(1.3)$ \\
\hline \multicolumn{3}{|l|}{ General or other } \\
\hline Yes, no. (\%) of nurses & $11(73)$ & $8(73)$ \\
\hline No. of years & $4.4(5.0)$ & $5.1(4.5)$ \\
\hline Full-time equivalent & $0.46(0.2)$ & $0.64(0.2)$ \\
\hline Patients & $n=304$ & $n=285$ \\
\hline Age, yr & $56(10)$ & $58(10)$ \\
\hline Sex, male, no. (\%) & $130(43)$ & $134(47)$ \\
\hline \multicolumn{3}{|l|}{ Socio-economic status, no. (\%) } \\
\hline High & $76(26)$ & $58(21)$ \\
\hline Intermediate & $123(42)$ & $105(38)$ \\
\hline Low & $92(32)$ & $112(41)$ \\
\hline Smokers, no. (\%) & $100(34)$ & $53(19) \ddagger$ \\
\hline Systolic blood pressure $(\mathrm{mm} \mathrm{Hg})$ & $144(19)$ & $150(19) \ddagger$ \\
\hline Hypertension, † no. (\%) & $186(62)$ & $198(71) \S$ \\
\hline Cholesterol ratio & $4.5(1.4)$ & $4.6(1.4)$ \\
\hline LDL cholesterol, $\mathrm{mmol} / \mathrm{L}$ & $3.7(1.0)$ & $3.8(1.0)$ \\
\hline Hypercholesterolemia, † no. (\%) & $151(51)$ & $104(37) \ddagger$ \\
\hline Glucose, $\mathrm{mmol} / \mathrm{L}$, & $5.8(1.0)$ & $6.0(1.6)$ \\
\hline Diabetes, no. (\%) & $34(11)$ & 49 (17)§ \\
\hline $\begin{array}{l}\text { Family history of cardiovascular disease, } \\
\text { no. }(\%)\end{array}$ & $138(45)$ & $95(33)$ \\
\hline Body mass index & $29(4.9)$ & $29(5.3)$ \\
\hline Obesity, no. (\%) & $117(39)$ & $95(33)$ \\
\hline 10-year risk of cardiovascular mortality & $4.3(4.9)$ & $5.4(6.3) \S$ \\
\hline High risk patients, no. (\%) & $85(28)$ & $112(39) \ddagger$ \\
\hline
\end{tabular}

Note: LDL = low-density lipoprotein, SD = standard deviation

*Unless stated otherwise.

tIncluded patients receiving medical treatment.

$\neq p \leq 0.01$ between groups.

$\S p \leq 0.05$ between groups. size calculation assumed an intraclass correlation coefficient of $0.02, \alpha$ of 0.05 and a power of 0.80 . Thus, a total of 450 patients (225 per group) were needed. To compensate for $20 \%$ loss to follow-up, we required a total of 580 patients $(29$ patients per practice, assuming 20 participating practices).

\section{Statistical analysis}

We examined the differences between the groups by use of the $t$ test for continuous variables (composite adherence score, consumption of fat, fruit and vegetables, and physical activity and 10year mortality risk from cardiovascular disease. We used a $\chi^{2}$ test for dichotomous variables (smoking and alcohol consumption).

The 6 lifestyle factors (smoking, consumption of alcohol, fat, fruit and vegetables, and physical activity) were further explored by multilevel regression analyses (backward procedure) in 6 models, with each lifestyle factor as a dependent variable. We controlled for group allocation, preintervention scores, patients' age, sex and socio-economic status, hypertension, hypercholesterolemia, diabetes and obesity. A random intercept was included in each model to account for the intracluster correlation. We adjusted for skewed distribution of data for certain outcomes, such as fruit and vegetables, by means of $\log$-transformation. To avoid zero values, we first added 1 to the data before logtransforming.

The 6 lifestyle factors were combined in a composite standardized adherence score expressing the agreement between a patient's lifestyle and the national recommendations. Meeting the national recommendation was scored as 1 , and not meeting it was scored as 0 . We used a $t$ test to compare the sum of the scores (0-6) of the intervention group with that of the control group.

We explored cardiovascular risk by use of a multilevel regression analysis, with cardiovascular risk as a dependent variable. We controlled for group allocation and preintervention score.

Finally, we examined differences between baseline and after 1 year by a paired $t$ test for continuous variables and a McNemar test for dichotomous variables.

All analyses were based on "intention to treat." The multilevel regression 
analyses with the dependent variables smoking and alcohol were only performed for patients who smoked or who consumed alcohol above the national recommendation at baseline. We considered $p \leq 0.05$ to be statistically significant.

\section{Results}

\section{Practices and patients}

We visited 29 practices. Four practices decided not to participate in the study, and 1 control practice withdrew after randomization. Thus, 13 practices were included in the intervention group and 11 in the control group (Figure 1).

We included 615 patients: 322 in the intervention group and 293 in the control group. In the intervention group, 56 patients were lost to follow-up after 1 year, and 39 were lost to follow-up in the control group. Thirty-two patients were excluded from data analyses because of incomplete data. We analyzed the lifestyle outcomes for 488 patients (79\%; 252 in the intervention group, 236 in the control group), and we analyzed the cardiovascular outcomes for 547 patients $(89 \%$; 286 in the intervention group, 261 in control group).

\section{Baseline characteristics}

The mean age of patients was 57 , and $55 \%$ were women (Table 1). In the intervention group, $34 \%$ were smokers, compared with $19 \%$ in the control group. There were more patients with diabetes $(17 \%)$ and hypertension $(71 \%)$ in the control group than in the intervention group (11\% with diabetes; $62 \%$ with hypertension). Patients in the control group had higher mean systolic blood pressure (150 mm Hg, standard deviation [SD] $19 \mathrm{~mm} \mathrm{Hg}$ ) and 10-year mortality risk from cardiovascular disease $(5.4 \%)$ compared with patients in the intervention group (mean systolic blood pressure 144 [SD 19] $\mathrm{mm} \mathrm{Hg}$; mean 10-year cardiovascular disease mortality risk $4.3 \%$ ).

\section{Outcomes}

The composite adherence score at baseline showed a mean number of national recommendations being met of 3.3 (out of a possible 6 points) in the intervention group and 3.4 in the control group. We found no significant difference between the groups after 1 year (Table 2); however, there was a significant improvement in the intervention group $(3.7, p<0.001)$,

Table 2: Main outcomes at baseline and at 1 year

\begin{tabular}{|c|c|c|c|c|c|c|}
\hline \multirow[b]{2}{*}{ Outcomes } & \multicolumn{3}{|c|}{ Baseline; mean (SD)* } & \multicolumn{3}{|c|}{ One year; mean $(S D) *$} \\
\hline & Intervention & Control & $p$ value & Intervention & Control & $p$ value \\
\hline & $n=304$ & $n=285$ & & $n=252$ & $n=236$ & \\
\hline Composite adherence score & $3.3(1.2)$ & $3.4(1.3)$ & 0.07 & $3.7(1.4)$ & $3.6(1.2)$ & 0.33 \\
\hline Smoking, yes, no. (\%) of patients & $100(34)$ & $53(19)$ & $<0.001$ & $68(27.3)$ & $40(17.5)$ & 0.011 \\
\hline Fat score & $16.6(5.7)$ & $17.2(5.3)$ & 0.19 & $14.4(5.4)$ & $15.4(5.4)$ & 0.034 \\
\hline $\begin{array}{l}\text { Met the NR for fat intake, }+ \text { no. }(\%) \\
\text { of patients }\end{array}$ & $123(41)$ & $93(33)$ & 0.049 & $140(56)$ & $111(47)$ & 0.06 \\
\hline No. of pieces of fruit eaten per week & $12.1(9.2)$ & $13.1(10.5)$ & 0.21 & $13.7(9.8)$ & $14.1(11.0)$ & 0.70 \\
\hline $\begin{array}{l}\text { Met the NR for fruit intake, } \neq \text { no. }(\%) \\
\text { of patients }\end{array}$ & $117(39)$ & $121(43)$ & 0.33 & $114(45)$ & $108(46)$ & 0.91 \\
\hline $\begin{array}{l}\text { Vegetables eaten per week, no. of } \\
\text { tablespoons }\end{array}$ & $23.7(11.2)$ & $22.7(12.9)$ & 0.32 & $25.5(12.7)$ & $23.4(13.3)$ & 0.09 \\
\hline $\begin{array}{l}\text { Met the NR for vegetable intake, } \S \text { no. } \\
(\%) \text { of patients }\end{array}$ & $95(32)$ & $79(29)$ & 0.48 & $93(39)$ & $65(30)$ & 0.045 \\
\hline $\begin{array}{l}\text { Drank alcohol, no. (\%) of patients } \\
\text { whose intake was above the NR** }\end{array}$ & $28(10)$ & $30(11)$ & 0.59 & $24(9.9)$ & $24(10.8)$ & 0.75 \\
\hline Physical activity, $† \dagger$ minutes per week & $405(343)$ & $447(345)$ & 0.16 & $460(362)$ & $449(365)$ & 0.74 \\
\hline \multirow{2}{*}{$\begin{array}{l}\text { Physical activity, no. (\%) who met } \\
\text { the NR§§ }\end{array}$} & $183(60)$ & $181(64)$ & 0.41 & $163(65)$ & $153(65)$ & 0.97 \\
\hline & $n=304$ & $n=285$ & & $n=286$ & $n=261$ & \\
\hline Systolic blood pressure, $\mathrm{mm} \mathrm{Hg}$ & $144(19)$ & $150(19)$ & 0.000 & $138(16)$ & $142(16)$ & 0.004 \\
\hline Cholesterol ratio & $4.5(1.4)$ & $4.6(1.4)$ & 0.45 & $4.3(1.3)$ & $4.3(1.3)$ & 0.77 \\
\hline 10-year cardiovascular risk & $4.3(4.9)$ & $5.4(6.3)$ & 0.025 & $3.8(4.1)$ & $4.7(5.5)$ & 0.023 \\
\hline High risk, no. (\%) of patients & $85(28)$ & $112(39)$ & 0.004 & $72(25)$ & $99(38)$ & $<0.001$ \\
\hline
\end{tabular}

Note: $\mathrm{NR}=$ national recommendation, $\mathrm{SD}=$ standard deviation.

*Unless otherwise stated.

$\dagger$ Total fat $\leq 100 \mathrm{~g} /$ day for men, $\leq 80 \mathrm{~g} /$ day for women; saturated fat $\leq 28 \mathrm{~g} /$ day for men, $\leq 22 \mathrm{~g} /$ day for women.

$\$ 200 \mathrm{~g} /$ day (2 pieces).

$\S 200 \mathrm{~g} /$ day.

$* * \leq 3$ units/day for men; $\leq 2$ units/day for women.

††Moderate or vigorous intensity.

$\S \S$ Accumulate 30 minutes or more of moderate-intensity physical activity (gardening, brisk walking, bicycling, housework, dancing) at least 5 days each week. 
and a nonsignificant improvement in the control group (3.6, $p=0.058)$. In the intervention group, there was a significantly lower intake of fat $(p=0.034)$ and a significantly higher percentage of patients who met the national recommendations for vegetable intake $(p=0.045)$ than in the control group (Table 2).

In the multilevel regression analyses, we found no relevant differences for all outcomes between the groups (Figure 2, Appendix 2 [available online at www.cmaj.ca/cgi/content/full /cmaj.081591/DC1]). We found significant differences for fat intake, vegetables consumption and physical activity, but these differences were small and only significant for subgroups.

After 1 year, there was no effect of the intervention on the absolute risk of 10 -year cardiovascular disease mortality because the difference at baseline remained (Table 2). Correction for baseline scores did not change this result, although the risk was significantly decreased in both the intervention (from $4.3 \%$ to $3.8 \%, p=0.047$ ) and control (from $5.4 \%$ to $4.7 \% p=0.004)$ groups.

\section{Interpretation}

We found that a nurse-led intervention, which included risk communication, a decision aid and motivational interviewing, did not improve the self-reported lifestyle factors or 10-year risk of cardiovascular disease mortality. Although we found improvements in some outcomes in both the intervention and control groups, there were only a few, small significant differences that were not clinically relevant between the groups.

We do not have one clear explanation for the lack of difference in effects between groups. One reason might be a lack of contrast between the performance of the nurses in the intervention and control groups. In our opinion, the control group was not a real control group but was in fact another intervention group. The practice nurses were very experienced and eager to participate in the study and were highly motivated to improve the quality of care. It seems that the nurses in our study were early adopters of innovations in primary care and that the overall performance of the nurses was high, which made it difficult to attain a contrast between the groups with one training course. In addition, motivational interviewing is a hot topic in the Netherlands, with many of the nurses eager to be trained in this technique. Further, a 2-day training course in motivational interviewing may have been too short to considerably improve the nurses' communication skills. Long-term additional training may be necessary to allow them to work in accordance with the principles of motivational interviewing. A second reason for the lack of difference between the groups may be because of the low-risk profile of the included patients. The intervention would probably have been more effective if high-risk patients had been included.

There is evidence that shared decision-making has a positive effect on intermediate outcomes such as decisional conflict, knowledge and realistic expectations ${ }^{41}$ however, the effect of shared decision-making on long-term health behaviour is not clear. ${ }^{42}$ The results of our study do not increase the clarity. The reduced 10-year risk in both groups was surprising in light of the relatively low-risk level of patients in this study. The improvements in lifestyle and 10-year risk after 1 year suggest that cardiovascular risk management by nurses can have a positive effect on these outcomes. In our view, these findings are promising. Earlier studies described cardiovascular prevention in rehabilitation projects ${ }^{1-3}$ or reported only small potential effects. ${ }^{4.5}$ We believe that preventive interventions by practice nurses keep motivated patients going in their attempts to improve their health behaviour. Recently, a study about nurses applying cardiovascular risk management in primary prevention showed promising withingroup results as well. ${ }^{43}$ However, the role of nurses in our study is more feasible and compatible with current care compared with the model used in that study, and our study used shared decision-making as the underlying model.

The real effects in terms of lifestyle change may be larger than what we found in our study, because the analysis also

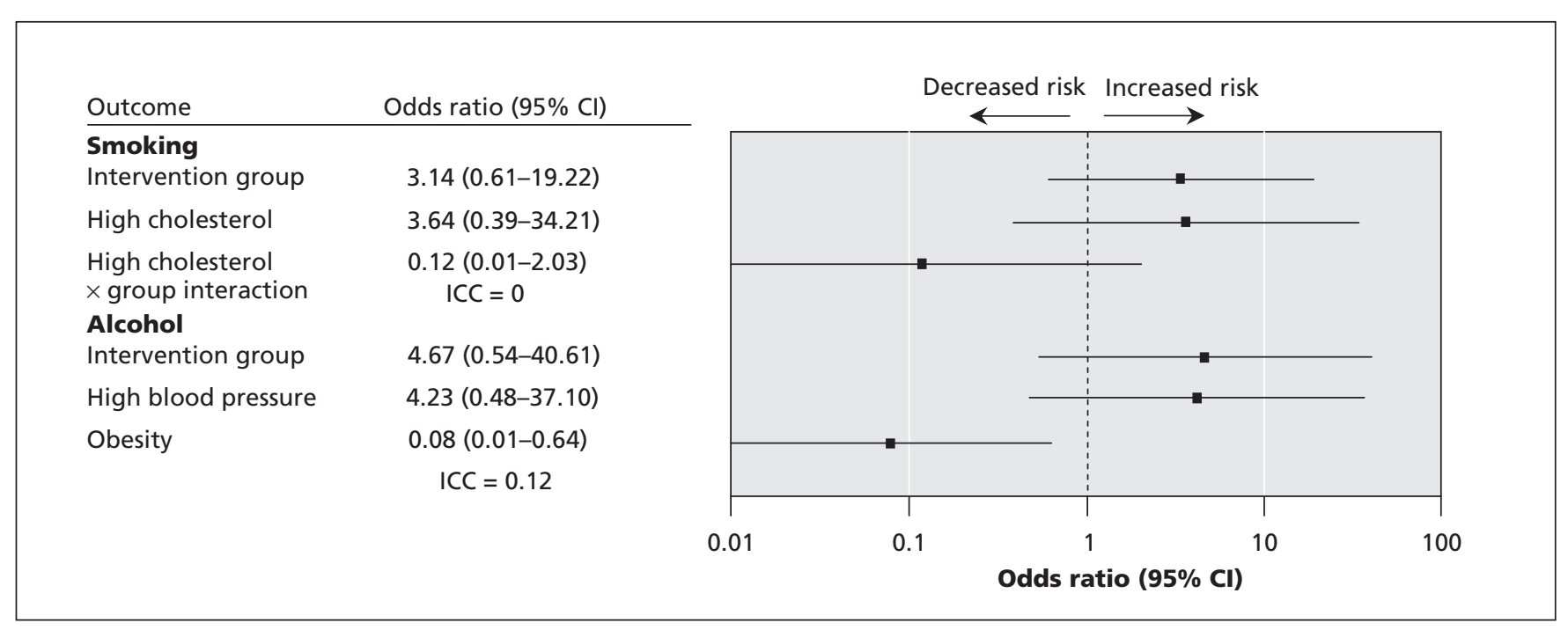

Figure 2: Multilevel logistic regression analysis of smoking $(n=114)$ and alcohol use $(n=48)$ at 1 year. Note: $\mathrm{Cl}=$ confidence interval, ICC = intraclass correlation coefficient. 
included patients who did not choose to change a specific lifestyle factor. This may have diminished the detectable effect in the intervention group. We interpret the significant differences between the groups with caution, because these results could be an overestimation because of multiple testing. Further, the 10-year risk at baseline was significantly lower in the intervention group than in the control group, thus reducing opportunities for improvement in the intervention group.

\section{Limitations}

The study was a cluster-randomized controlled trial in real practices. There were some imbalances between the groups at baseline that may have been caused by the relatively small number of clusters. Despite our careful design, there was some recruitment bias. There were significantly more smokers in the intervention group than in the control group, possibly because some nurses had already been trained in motivational interviewing by STIVORO, the Dutch smoking prevention agency. The significantly higher number of patients with diabetes in the control group than in the intervention group may have been because nurses in the control group have more experience with patients with diabetes (Table 1). Recruitment bias after randomization is a wellknown problem in cluster-randomized controlled trials. ${ }^{44} \mathrm{We}$ minimized the influence of this bias on the results by controlling for patient characteristics. Controlling the recruitment of patients was not desirable, because we wanted to maintain high external validity. The number of included patients was sufficient, as determined by our power calculation.

\section{Conclusion}

We found no additional effect of a nurse-led intervention, including risk communication, decision support and adaptive motivational interviewing, on lifestyle factors and 10-year risk of cardiovascular mortality among patients in primary care. We are nevertheless cautious about concluding that the intervention has no valuable effect, because the nurses in the control group also seemed to be very experienced. Because of the low cost per patient, investments to implement the intervention could be worthwhile if the experiences with the intervention among practice nurses and patients are positive. Economic and process evaluation are needed to determine the value of further implementation.

\section{This article has been peer reviewed.}

\section{Competing interests: None declared.}

Contributors: Marije Koelewijn-van Loon was involved in the development of the intervention and instruments, recruitment of practices, data analyses and the reporting of results. Trudy van der Weijden was project leader of the Improving Patient Adherence to Lifestyle Advice (IMPALA) study and was involved in all aspects of the study. Ben van Steenkiste was involved in all aspects of the study, especially with regard to the decision aid, instruments, analyses and economic evaluation. Gaby Ronda was involved in all aspects of the effect and process evaluation, especially with regard to motivational interviewing and instruments to measure lifestyle changes. Bjorn Winkens advised the project team on the statistical analyses of this study. Johan Severens advised the project team on the economic evaluation. Michel Wensing advised the project team on the intervention, measurement instruments and design. Glyn Elwyn was involved in all aspects of the study, especially with regard to shared decision-making and provided advice on data analyses and reporting. Richard Grol was involved in all aspects of the study, provided advice on the design, analyses and reporting of the study data. All of the authors revised the manuscript critically and approved the final version submitted for publication.

Funding: This study was funded by a grant from the Netherlands Organisation for Health Research and Development (project number 946-04-055) and by Maastricht University.

\section{REFERENCES}

1. Jolliffe JA, Rees K, Taylor RS, et al. Exercise-based rehabilitation for coronary heart disease. Cochrane Database Syst Rev 2001;(1):CD001800.

2. Ades PA, Pashkow FJ, Nestor JR. Cost-effectiveness of cardiac rehabilitation after myocardial infarction. J Cardiopulm Rehabil 1997;17:222-31.

3. van Berkel TF, Boersma H, Roos Hesselink JW, et al. Impact of smoking cessation and smoking interventions in patients with coronary heart disease. Eur Heart $J$ 1999;20:1773-82.

4. Ebrahim S, Beswick A, Burke M, et al. Multiple risk factor interventions for primary prevention of coronary heart disease. Cochrane Database Syst Rev 2006;(4): CD001561.

5. Hooper L, Summerbell CD, Higgins JP, et al. Reduced or modified dietary fat for preventing cardiovascular disease. Cochrane Database Syst Rev 2001;(3): CD002137.

6. Nederlands Huisartsen Genootschapp. M84 NHG-standard cardiovasculair risicomanagement (Dutch guideline for cardiovascular risk management). Houten (the Netherlands): Bohn Stafleu van Loghum; 2006.

7. Laurant M, Reeves D, Hermens R, et al. Substitution of doctors by nurses in primary care. Cochrane Database Syst Rev 2005;(2):CD001271.

8. Laurant MG, Hermens RP, Braspenning JC, et al. Impact of nurse practitioners on workload of general practitioners: randomised controlled trial. BMJ 2004:328:927.

9. McGinnis JM, Foege WH. Actual causes of death in the United States. JAMA 1993;270:2207-12.

10. Mokdad AH, Marks JS, Stroup DF, et al. Actual causes of death in the United States, 2000. JAMA 2004;291:1238-45.

11. De Backer G, Ambrosioni E, Borch-Johnsen K, et al. European guidelines on cardiovascular disease prevention in clinical practice. Third Joint Task Force of European and Other Societies on Cardiovascular Disease Prevention in Clinical Practice. Eur Heart J 2003;24:1601-10.

12. Burke LE, Dunbar-Jacob JM, Hill MN. Compliance with cardiovascular disease prevention strategies: a review of the research. Ann Behav Med 1997;19:239-63.

13. Ashenden R, Silagy C, Weller D. A systematic review of the effectiveness of promoting lifestyle change in general practice. Fam Pract 1997;14:160-76.

14. Lutfey KE, Wishner WJ. Beyond "compliance" is "adherence." Improving the prospect of diabetes care. Diabetes Care 1999;22:635-9.

15. Sabate E. Adherence to long-term therapies. Evidence for action. Geneva (Switzerland): World Health Organization; 2003.

16. Roter DL, Hall JA, Merisca R, et al. Effectiveness of interventions to improve patient compliance: a meta-analysis. Med Care 1998;36:1138-61

17. Eifel P, Axelson JA, Costa J, et al. National Institutes of Health Consensus Development Conference Statement: adjuvant therapy for breast cancer, November 1-3, 2000. J Natl Cancer Inst 2001;93:979-89.

18. O'Connor AM, Legare F, Stacey D. Risk communication in practice: the contribution of decision aids. BMJ 2003;327:736-40.

19. Elwyn G, Edwards A, Britten N. What information do patients need about medicines? "Doing prescribing": how doctors can be more effective. BMJ 2003;327:864-7.

20. Car J, Sheikh A. Telephone consultations. BMJ 2003;326:966-9.

21. Koelewijn-van Loon MS, van Steenkiste B, Ronda G, et al. Improving Patient Adherence to Lifestyle Advice (IMPALA): a cluster-randomised controlled trial on the implementation of a nurse-led intervention for cardiovascular risk management in primary care (protocol). BMC Health Serv Res 2008;8:9.

22. Edwards A, Unigwe S, Elwyn G, et al. Personalised risk communication for informed decision making about entering screening programs. Cochrane Database Syst Rev 2003;(1):CD001865.

23. Stevens RJ, Kothari V, Adler AI, et al. The UKPDS risk engine: a model for the risk of coronary heart disease in type II diabetes (UKPDS 56). Clin Sci (Lond) 2001;101:671-9.

24. Feldman-Stewart D, Kocovski N, McConnell BA, et al. Perception of quantitative information for treatment decisions. Med Decis Making 2000;20:228-38.

25. Lipkus IM, Hollands JG. The visual communication of risk. J Natl Cancer Inst Monogr 1999;25:149-63.

26. Edwards A, Elwyn G, Covey J, et al. Presenting risk information - a review of the effects of "framing" and other manipulations on patient outcomes. J Health Commun 2001;6:61-82.

27. Timmermans D, Molewijk B, Stiggelbout A, et al. Different formats for communicating surgical risks to patients and the effect on choice of treatment. Patient Educ Couns 2004;54:255-63.

28. van Steenkiste B, van der Weijden T, Stoffers HE, et al. Improving cardiovascular risk management: a randomized, controlled trial on the effect of a decision support tool for patients and physicians. Eur J Cardiovasc Prev Rehabil 2007;14:44-50.

29. Rollnick S, Miller WR. What is motivational interviewing? Behav Cogn Psychother 1995;23:325-34. 


\section{RESEARCH}

30. Burke BL, Arkowitz H, Menchola M. The efficacy of motivational interviewing: meta-analysis of controlled clinical trials. J Consult Clin Psychol 2003;71:843-61.

31. Rollnick S, Mason P, Butler C. Health behavior change. A guide for practitioners. 1st ed. London (UK): Churchill Livingstone; 1999.

32. Rubak S, Sandbaek A, Lauritzen T, et al. Motivational interviewing: a systematic review and meta-analysis. Br J Gen Pract 2005;55:305-12.

33. Mudde AN, Willemsen MC, Kremers S, et al. Meetinstrumenten voor onderzoek naar roken en stoppen met roken. Den Haag: Stivoro, 2000.

34. van Assema P, Brug J, Ronda G, et al. The relative validity of a short Dutch questionnaire as a means to categorize adults and adolescents to total and saturated fat intake. Journal of human nutrition and dietetics 2001;14:377-90.

35. Van Assema P, Brug J, Ronda G, et al. A short Dutch questionnaire to measure fruit and vegetable intake: relative validity among adults and adolescents. Nutr Health 2002;16:85-106.

36. Harada ND, Chiu V, King AC, et al. An evaluation of three self-report physical activity instruments for older adults. Med Sci Sports Exerc 2001;33:962-70.

37. Conroy RM, Pyorala K, Fitzgerald AP, et al. Estimation of ten-year risk of fatal cardiovascular disease in Europe: the SCORE project. Eur Heart J 2003;24:9871003 .

38. Burgers JS, Simoons ML, Hoes AW, et al. Richtlijn Cardiovasculair Risicomanagement. Ned Tijdschr Geneeskd 2007;151:1068-74.

39. Stevens RJ, Kothari V, Adler AI, et al. The UKPDS risk engine: a model for the risk of coronary heart disease in Type II diabetes (UKPDS 56). Clin Sci (Lond) 2001;101:671-9.
40. Perera R, Heneghan C, Yudkin P. Graphical method for depicting randomised trials of complex interventions. BMJ 2007;334:127-9.

41. O'Connor AM, Stacey D, Entwistle V, et al. Decision aids for people facing health treatment or screening decisions. Cochrane Database Syst Rev 2003;(2): CD001431.

42. Joosten EA, DeFuentes-Merillas L, de Weert GH, et al. Systematic review of the effects of shared decision-making on patient satisfaction, treatment adherence and health status. Psychother Psychosom 2008;77:219-26.

43. Wood DA, Kotseva K, Connolly S, et al. Nurse-coordinated multidisciplinary, family-based cardiovascular disease prevention programme (EUROACTION) for patients with coronary heart disease and asymptomatic individuals at high risk of cardiovascular disease: a paired, cluster-randomised controlled trial. Lancet 2008;371:1999-2012.

44. Puffer S, Torgerson D, Watson J. Evidence for risk of bias in cluster randomised trials: review of recent trials published in three general medical journals. BMJ 2003;327:785-9.

Correspondence to: Marije S. Koelewijn-van Loon, Maastricht University, CAPHRI School for Public Health and Primary Care, Department of General Practice, PO Box 616, 6200 MD Maastricht, the Netherlands; M.Koelewijn@HAG.unimaas.nl 